\title{
Modulation of insulin resistance by renin angiotensin system inhibitors: implications for cardiovascular prevention
}

\author{
Valeria Valente ${ }^{1}$, Raffaele Izzo $^{2}$, Maria Virginia Manzi², Maria Rosaria De Luca1, Emanuele Barbato ${ }^{1}$, \\ Carmine Morisco ${ }^{1}$ \\ ${ }^{1}$ Department of Translational Medicine; ${ }^{2}$ Department of Advanced Biomedical Sciences, University of Naples Federico II, \\ Naples, Italy
}

\begin{abstract}
Insulin resistance (IR) and the related hyperinsulinamia play a key role in the genesis and progression of the continuum of cardiovascular (CV) disease. Thus, it is reasonable to pursue in primary and secondary $\mathrm{CV}$ prevention, the pharmacological strategies that are capable to interfere with the development of IR. The renin-angiotensin-aldosterone system (RAAS) plays an important role in the pathogenesis of IR. In particular, angiotensin II (Ang II) through the generation of reactive oxygen species, induces a low grade of inflammation, which impairs the insulin signal transduction. The angiotensin converting enzyme (ACE) inhibitors are effective not only as blood pressure-lowering agents, but also as modulators of metabolic abnormalities. Indeed, experimental evidence indicates that in animal models of IR, ACE inhibitors are
\end{abstract}

Correspondence: Prof. Carmine Morisco, Dipartimento di Scienze Biomediche Avanzate, Università degli Studi Federico II, Via S. Pansini 5, 80131 Napoli, Italy.

E-mail: carmine.morisco@unina.it

Authors' contributions: VV, CM, study concept; RI, MVM, MRDL, literature search; $\mathrm{CM}$, manuscript drafting; EB, critical revision. All the authors made a substantive intellectual contribution, have read and approved the final version of the manuscript and agreed to be accountable for all aspects of the work.

Key words: Insulin receptor; Angiotensin converting enzyme inhibitors; Angiotensin II receptor blockers; cardiovascular risk.

Ethics approval: Not applicable.

Conflict of interest: None.

Acknowledgments: The Authors are grateful to Federica De Luise for her technical assistance in the preparation of the manuscript.

Received for publication: 8 September 2020.

Accepted for publication: 28 December 2020.

${ }^{\circ}$ Copyright: the Author(s), 2021

Licensee PAGEPress, Italy

Monaldi Archives for Chest Disease 2021; 91:1602

doi: 10.4081/monaldi.2021.1602

This article is distributed under the terms of the Creative Commons Attribution Noncommercial License (by-nc 4.0) which permits any noncommercial use, distribution, and reproduction in any medium, provided the original author(s) and source are credited. capable to ameliorate the insulin sensitivity. The Ang II receptor blockers (ARBs) modulate the peroxisome proliferator-activated receptor (PPAR) $\gamma$ activity. PPAR $-\gamma$ is a transcription factor that controls the gene expression of several key enzymes of glucose metabolism. A further mechanism that accounts for the favorable metabolic properties of ARBs is the capability to modulate the hypothalamic-pituitary-adrenal (HPA) axis. The available clinical evidence is consistent with the concept that both ACE inhibitors and ARBs are able to interfere with the development of IR and its consequences like type 2 diabetes. In addition, pharmacological inhibition of the RAAS has favourable effects on dyslipidaemias, metabolic syndrome and obesity. Therefore, the pharmacological antagonism of the RAAS, nowadays, represents the first choice in the prevention of cardio-metabolic diseases.

\section{Insulin resistance and carsdiovascular risk}

Insulin resistance (IR) and the related hyperinsulinamia play a key role in the genesis and progression of the continuum of cardiovascular $(\mathrm{CV})$ disease. In particular, IR is a complex and multifaceted pathogenic mechanism that accounts for the development of CV risk factors, such as type 2 diabetes (T2D), metabolic syndrome (MS), obesity, hypertension, and non-alcoholic fatty liver disease (NAFLD) [1-4]. Furthermore, IR participates to the development and progession of target organ damage (TOD) as left ventricular hypertrophy (LVH), chronic kidney disease (CKD), and atherosclerosis [5-8]; and, is involved in the occurrence of major CV events such as myocardial infarction, ischemic stroke, and heart failure [913]. Thus, given the strong relationships between IR and CV risk, it is reasonable to pursue in primary and secondary $\mathrm{CV}$ prevention, the pharmacological strategies that are capable to interfere with the development of IR and its complicances.

Abnormalities of insulin signaling transduction account for the development of IR. At this regard, it has been documented that dysregulation of the renin-angiotensin-aldosterone system (RAAS) plays a key role in the pathogenesis of IR [14]. In particular, angiotensin II (Ang II), through the generation of reactive oxygen species (ROS), promotes the proteasome-mediated degradation of insulin receptor substrate-1 (IRS-1) [14] resulting in the impairment of insulin action. This effect, at vascular level induces a low grade of inflammation, which accounts for the development of IR and subsequent CV events [15]. Therefore, the pharmacological inhibition of the RAAS, obtained either with angiotensin converting enzyme (ACE) inhibitors or with Ang II receptor blockers (ARBs), nowadays, represents the first choice in primary and secondary $\mathrm{CV}$ prevention. 


\section{RAAS inhibithors}

According the classic view, the RAAS plays a key role in the regulation of blood pressure (BP) homeostasis. Dysregulation of the RAAS results in the increase of stimulation of type 1 Ang II receptors (AT1R) wich is involved in the pathogenesis of hypertension and TOD. In addition, enhanced stimulation of AT1 R has been reported also in T2D, MS, obesity, and NAFLD.

\section{ACE inhibitors}

The ACE inhibitors are effective not only as BP-lowering agents, but also as modulators of metabolic abnormalities. Basically, ACE inhibitors have two primary mechanisms that mediate their influences on hemodynamic and metabolic homeostasis. First, ACE inhibitors decrease the conversion of angiotensin I to Ang II; in addition, via the inhibition of the kininase II breakdown [16], they enhance the circulating level of the bradykinin (Figure 1). The higher kinin levels lead to an increased production of prostaglandins (prostaglandin E1 and prostaglandin E2) and nitric oxide (NO) that improve exercise-induced glucose metabolism and muscle sensitivity to insulin [17,18], resulting in enhanced insulin-mediated glucose uptake. Furthermore, the peripheral vasodilatory actions of ACE inhibitors increase the surface area for glucose exchange between the vascular bed and skeletal muscles. Clinical evidence supporting this effect has been provided by Morel et al. [19], who have demonstrated improved insulin sensitivity when enalapril was given for 12 weeks in patients at high CV risk. A similar effect has also been reported with captopril [20]. However, it should be underlined that this can not be considered the only mechanism that account for the increase of insulin sensitivity because this action is not shared by drugs that acts exclusively as vasodilators like hydralazine. Moreover, the protection against the development of IR may be partially due to the regulation of adipocyte cell cycle. In fact, it has been demonstrated that increased levels of Ang II inhibit the differentiation of pre-adipocyte into mature adipocytes, compromising the fat cells' ability to store fat. This, in turn, results in shunting of fats to the liver, skeletal muscle, and pancreas. This phenomenon compromises the insulin sensitivity. Reducing Ang II levels with an ACE inhibitor or blocking the AT1R may promote the differentiation of pre-adipocytes to mature adipocytes, which serve as a sump for fat. In addition, redistribution of the lipids from the peripheral tissues would improve insulin sensitivity [21]. A further mechanism that accounts for the favourable effect of ACE inhibitors on insulin sensitivity relates to the protective action on the pancreatic beta cell. In particular, the inhibition of the vasoconstrictive effect of Ang II

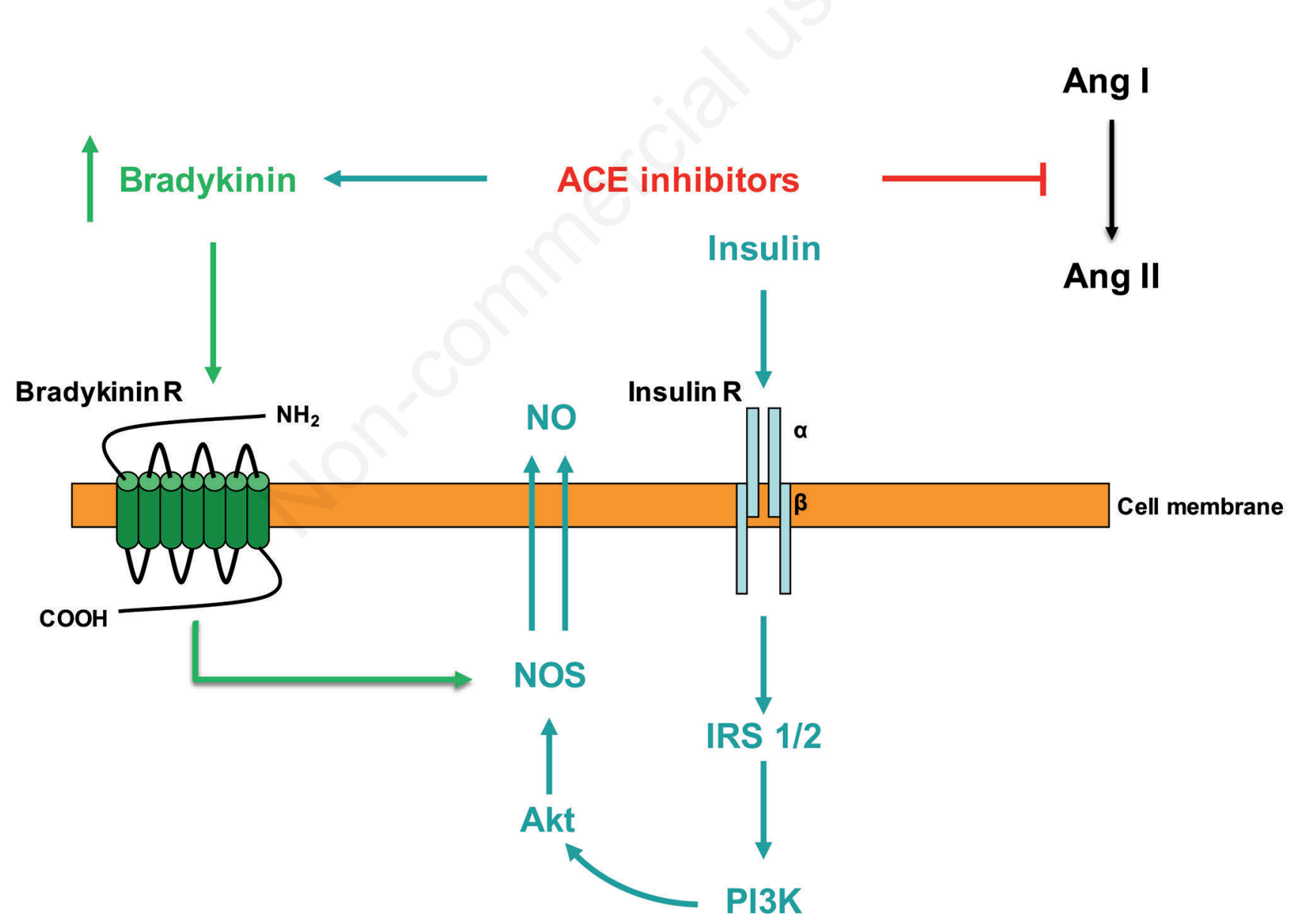

Figure 1. Schematic representation of mechanisms of the ACE inhibitors. Angiotensin converting enzyme (ACE) inhibitors, reduce Angiotensin (Ang) II production, and at the same time, inhibit the breakdown of bradykinin, which, in turn interacts with its own receptor. Thsese effects together with the recovery of insulin signaling result in an increased NOS activation and NO production. IRS, insulin receptor substrate; PI3K, phosphatidyl-inositol 3-kinase; NOS, nitric oxide synthase; NO, nitric oxide. 
in the pancreas increases the islet blood flow [22], resulting in the enhanced release of insulin by beta cells.

There are several experimental and clinical epidemiological data that indicate that ACE inhibitors improve the glucose metabolism in different tissue and organs.

\section{Experimental data}

There are experimental studies performed in animal models of hypertension and IR that have demonstrated that acute and/or chronic administration of ACE inhibitors can improve insulin action on whole-body and skeletal muscle glucose disposal. In particular, it has been demonstrated that the acute infusion of captopril in obese Zucker rats, a murine model of IR enhances insulin sensitivity during a hyperinsulinemic euglycemic clamp [23]. A similar response to acute infusion of captopril has been observed in an insulin resistant diabetic dog model [24]. In addition, also chronic treatment with ACE inhibitors is able to enhance glucose tolerance. In fact, it has been shown that chronic administration of ACE inhibitors in obese Zucker rats elicits an increase in whole-body insulin action. Chronic oral treatment of obese Zucker rats with the ACE inhibitors captopril [25], trandolapril [26] or imidapril [27] causes substantial improvements in whole-body insulin sensitivity. Interestingly, the ACE inhibitor-mediated improvements in whole-body insulin sensitivity were also associated with decrease in plasma insulin levels and amelioration of lipid profile. Chronic administration of ACE inhibitor in a mouse model of T2D also significantly improves whole-body glucose tolerance and insulin sensitivity [28].

The skeletal muscle is principal target of the metabolic action of ACE inhibitors. In fact, acute administration of the ACE inhibitors captopril [29] or trandolapril [30] significantly enhances insulin-mediated glucose transport activity in skeletal muscle in the obese Zucker rat. ACE inhibitors can beneficially modulate glucose metabolism also in cardiac muscle. Rett et al. [31] have demonstrated in cardiac muscle of the obese Zucker rat using the perfused Langendorff preparation, that the acute administration of bradykinin can significantly increase insulin-stimulated glucose transport activity. The traslocation process of both GLUT1 and GLUT4 mediates this effect.

NAFLD is the hepatic feature of hyperclaoric diet-induced IR [32]. At this regard, it has been documented that Inhibition of RAAS obtained either with ACE inhitiotors (perindopril) or with ARBs (Ibesartan) is able to prevent the developmet of IR and liver steatosis in obese Zucker rat, through the reduction of inflammatory mediators like tumor necrosis factor-alpha (TNF-alpha), interleukin-6 (IL6) and transforming growth factor-beta1 (TGF-beta1) [33].

Experimental evidence indicates that in animal models of IR, ACE inhibitors are capable to ameliorate the insulin sensitivity, and this effect is independent from their antihypertensive action.

\section{Clinical data}

The beneficial effects of ACE inhibitors to improve IR come from several observational and interventional studies in human subjects. Since the IR is the principal pathogenic mechanism involved in the development of T2D, it is reasonable to assume that all terapeurtic interventions that are able to prevent the incidence of T2D, improve the insulin sensitivity. In the Captopril Prevention Project (CAPPP) [34] and the Heart Outcomes Prevention Evaluation (HOPE) study [35], two large prospective studies involving subjects at risk for developing T2D, there was a lesser incidence of newly-diagnosed T2D in those subjects who received an ACE inhibitor (either captopril or ramipril) compared to the respective placebo control groups. These data were con- firmed by the Antihypertensive and Lipid-Lowering Treatment to Prevent Heart Attack Trial (ALLHAT) study [36] which compared in subjects with hypertension the ACE inhibitor lisinopril vs chlorthalidone, and by the Prevention of Events with Angiotensin Converting Enzyme Inhibition (PEACE) Trial [37], which compared in subjects with coronary heart diseasae the ACE inhibitor Trandolapril vs placebo. The available clinical evidence are consistent with the concept that ACE inhibitors are able to interfere with the development of IR and its consequences.

\section{Angiotensin receptor blockers}

The hemodynamic and metabolic effects of Ang II are mediated by two different seven trans-membreane domains, G-proteincopuled receptors: AT1R and Ang II type 2 receptor (AT2R). The AT1Rs are widely expressed in adult organs and tissues and mediate the biological effects of Ang II, like sodium and water retention, increase of vascular peripheral resistances, activation of inflammatory response and pro-trombotic state, activation of sympathetic nervous system. AT2Rs are expressed during the fetal life and in pathological states. It has been hypothesized that stimulation of AT2R exerts an important role in counterbalancing some of the detrimental effects of Ang II. However, in the last decade, has emerged that the majority of Ang II-mediated effects are counterbalanced by the peptide Ang-(1-7). This peptide is synthesized from Ang II by an ACE homolog: ACE2 and binds to the G-protein-coupled receptor: Mas. It has been demonstrated that the pathway ACE2/Ang-(1-7)/Mas increases the NO production, exerts an anti-proiliferative, anti-thrombotic, anti-inflammatory actions [38]. Thus, the block of AT1R by ARBs increases the systemic and local levels of Ang II which are available to be transformed by ACE2 in Ang-(1-7), which, in turn, binds the Mas receptors. Additionally, in the pathological conditions the increased levels of Ang II result in the unopposed stimulation of the AT2R (Figure 2).

\section{Experimental data}

ARBs improve the insulin sensitivity not only by bloking the AT1R, but also through additional mechanisms. In particular, its has been demonstrated that Telmisartan, Eprosartan, Ibesartan and Losartan act as a peroxisome proliferator-activated receptor (PPAR)- $\gamma$ agonists $[39,40]$. PPAR- $\gamma$ is a transcription factor that controls the gene expression of several key enzymes of glucose metabolism, and thereby increases insulin sensitivity and preserves pancreatic beta-cell function. The first PPAR identified was PPAR$\alpha$, which is the target of fibrates. PPAR- $\gamma$ is the target of thiazolidinediones, a class of drugs that enhance insulin sensitivity. The pharmacological activation of both PPAR- $\alpha$, and PPAR- $\gamma$ provides metabolic benefits $[41,42]$. A further mechanism that accounts for the favorable metabolic properties of ARBs, is the capability to modulate the hypothalamic - pituitary-adrenal (HPA) axis. It has been reported, in murine model of IR, that Ang II-mediates the hyperactivity of HPA axis [43]. Of note, the treatment with AT1R antagonist Telmisartan was able to blunt the centrally-mediated effects of Ang II. The capability of ARBs to restore the metabolic homeostasis explains, in part, their effects also to prevent the liver fibrosis in animal models of IR [38].

\section{Clinical data}

The revision of 12 randomized controlled clinical trials with ACE inhibitors or ARBs aimed to evaluate the efficacy of these 
medications in T2D prevention, showed that ACE inhibitors and ARBs produced a $25 \%$ reduction (or a decrease from 17.4 to 14.3 cases per 1000 patient-years) in the incidence of new-onset of T2D [44]. This analysis involved 72,333 non-diabetic patients (approximately 338,000 patient-years of follow-up), with mean duration of follow-up ranged from 1 to 6.1 years. These data were substantially confirmed by a further meta-analysis [45]. Of note, the resuts of the Trascend Study were not included in both analyses since they were published later [46]. The clinical implications of these meta-analyses are consistent with concept that the inhibition of RAAS interferes with the development of T2D (Figure 3). Therefore, it is possible to speculate that the inhibition of RAAS obtained with either ACE inhibitors or ARBs ameliorates insulin sensitivity.

\section{Metabolic effects of RAAS inhibition}

IR is a complex pathogenic mechanism that can account for differents phenotypes, such as essential hypertension, T2D, MS, obesity, NAFLD, and different forms of vascular, cardiac and renal damage. Of note that the combination of different manifestations of IR increases the CV risk [47].

\section{Dyslipidaemias}

IR directly affects the lipidid homeostasis acting mainly through the inflammation and generation of ROS. Of note, these pathogenic mechanisms are, in part, mediated by Ang II. In addition, it ihas been documented that Ang II exerts several effects that influence atherogenic properties of cholesterol.

\section{Experimental data}

It has been demonstrated that AT1R genetic ablation has a significat effect in reducing hypercholesterolemia-induced atherosclerosis in low density lipoprotein (LDL) receptor-negative mice [48]. In this experimental setting, hypercholesterolemia was associated with increased systemic angiotensinogen and angiotensin peptides, which were reduced in AT1R-deficient mice. Together these data indicate that LDL-cholesterol contributes to development of atherosclerosis through a RAASdependent mechanism. Moreover, it has been reported in primary cultures of human monocyte-macrophages, that the pro-atherogenic effects of Ang II are related to upregulate the expression of Acyl-CoA:cholesterol acyltransfeRAASe-1 (ACAT1) [49]. This enzyme converts free cholesterol into esters for storage in lipid droplets. This process could promote foam cell formation and increase cholesterol content of atherosclerotic lesions. Finally, Ang II increases the oxidation of LDL in macrophage cell lines

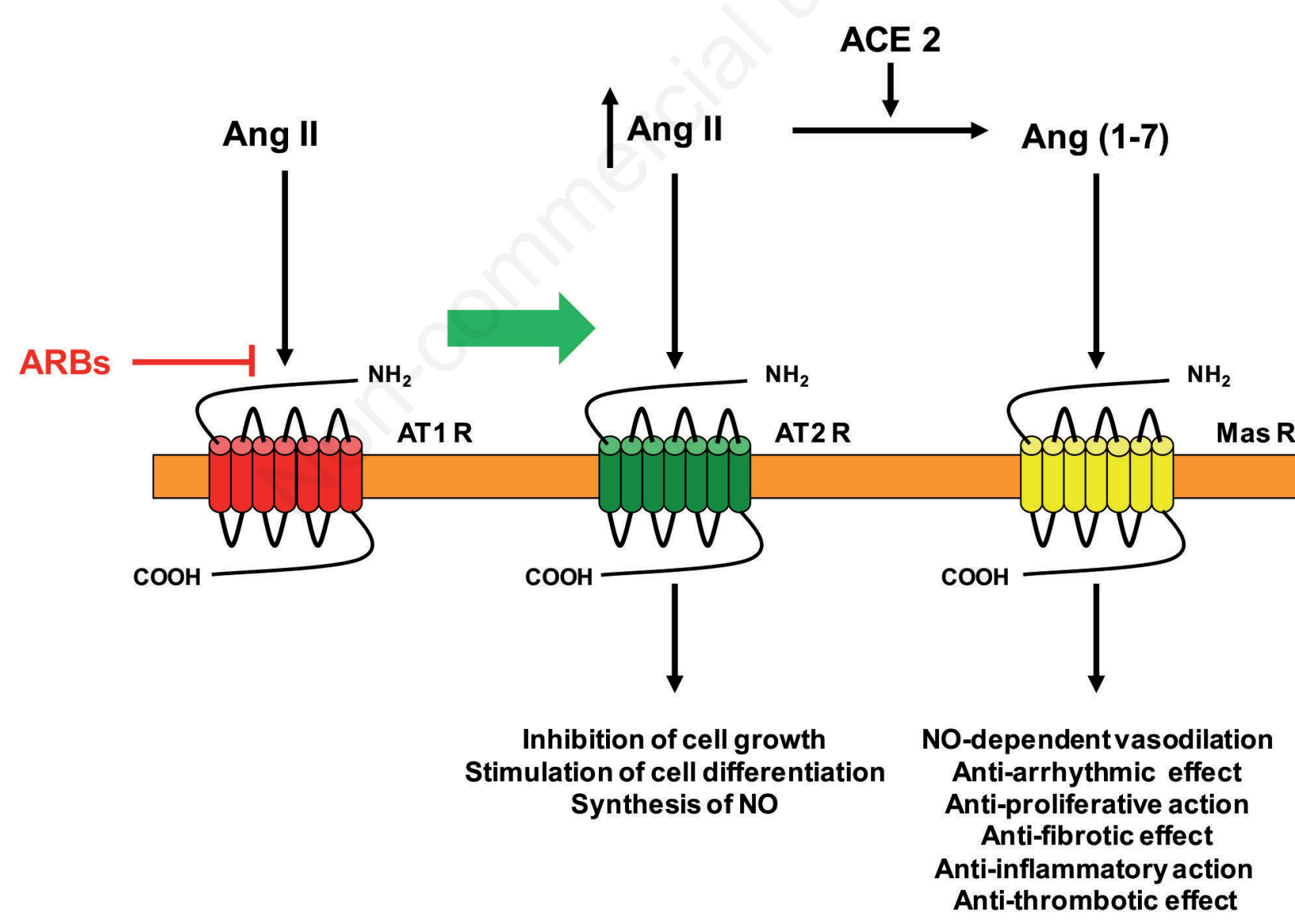

Figure 2. Schematic representation of mechanisms of the Ang II receptor blockers. The Angiotensin II receptor blockers (ARBs) block the binding of Angiotensin II (Ang II) with type 1 Ang II receptors (AT1R). This phenomenon increases the systemic and local levels of Ang II which bind to the Ang II type 2 receptor (AT2R) are transformed by Angiotensin converting enzyme (ACE) 2 in the peptide Ang-(1-7), which, in turn, binds the Mas receptors (MAS R). 
as well as mouse peritoneal macrophages, possibly through activation of NADPH oxidase. Altogether these observations are consistent with the notion that Ang II may influence the atherogenic properties of cholesterol through a redox inbalance without changing its blood concentrations [50]. On the other hand, cholesterol is able to regulate the RAAS activity. In particular, it has been demonstrated the capability of LDL-cholesterol to increase AT1R gene expression on vascular smooth muscle cells. Similarly, oxidized LDL can also increase AT1R gene expression in human coronary artery endothelial cells [51]. Together, these results clearly demonstrate a cross-talk between hypercholesterolemia and RAAS in the development of atherosclerosis and its clinical consequences. The lack of counteregulatory effect of insulin, in insulin resistant state, has a detrimental effect on this phenomenon.

\section{Clinical data}

Dyslipidaemias affects the incidence and the prognosis of $\mathrm{CV}$ diseases. Indeed, achievement of low levels of LDL-cholesterol protects against the development of atherosclerosis, and also prevents the long-term complications of myocardial infarction such as, post-infartual left ventricular remodeling [52]. Interventional studies have demonstrated that the pharmacological interference of RAAS, slightly improves the lipid profile. This beneficial action has been demonstrated for the different ARBs. In particular, Kyvelou et al. demonstrated, in a cohort of 2438 hypertensive patients, followed for 6 months, that ARBs-based monotherapy treatment induces a significant reduction of total and LDL-cholesterol, in addition increases the high density lipoproteins (HDL)-cholesterol [53] Furthermore, a sub-study of the LIFE trial showed in hypertensive patients that, in comparison to atenolol, losartan-based regimen, induces a less decrease in HDL-cholesterol; and this pharmacological effect is associated with a better prognosis [54]. The authors speculated that less the decrease of HDL-cholesterol may explain around one third of the beneficial effect of losartan-based compared to atenolol-based antihypertensive treatment on composite end-point found in the study. The favorable effects on lipid profile have been documented for ARBs also when these are combined with drugs that worsen the metabolic profile. In particular, the Alpine Study showed that treatment with diuretics, if needed, in combination with a $\beta$ blocker was associated with a worsening of metabolic profile; this effect was not detected for patients treated with an ARBs [55]. As above mentioned, some ARBs, have been reported to

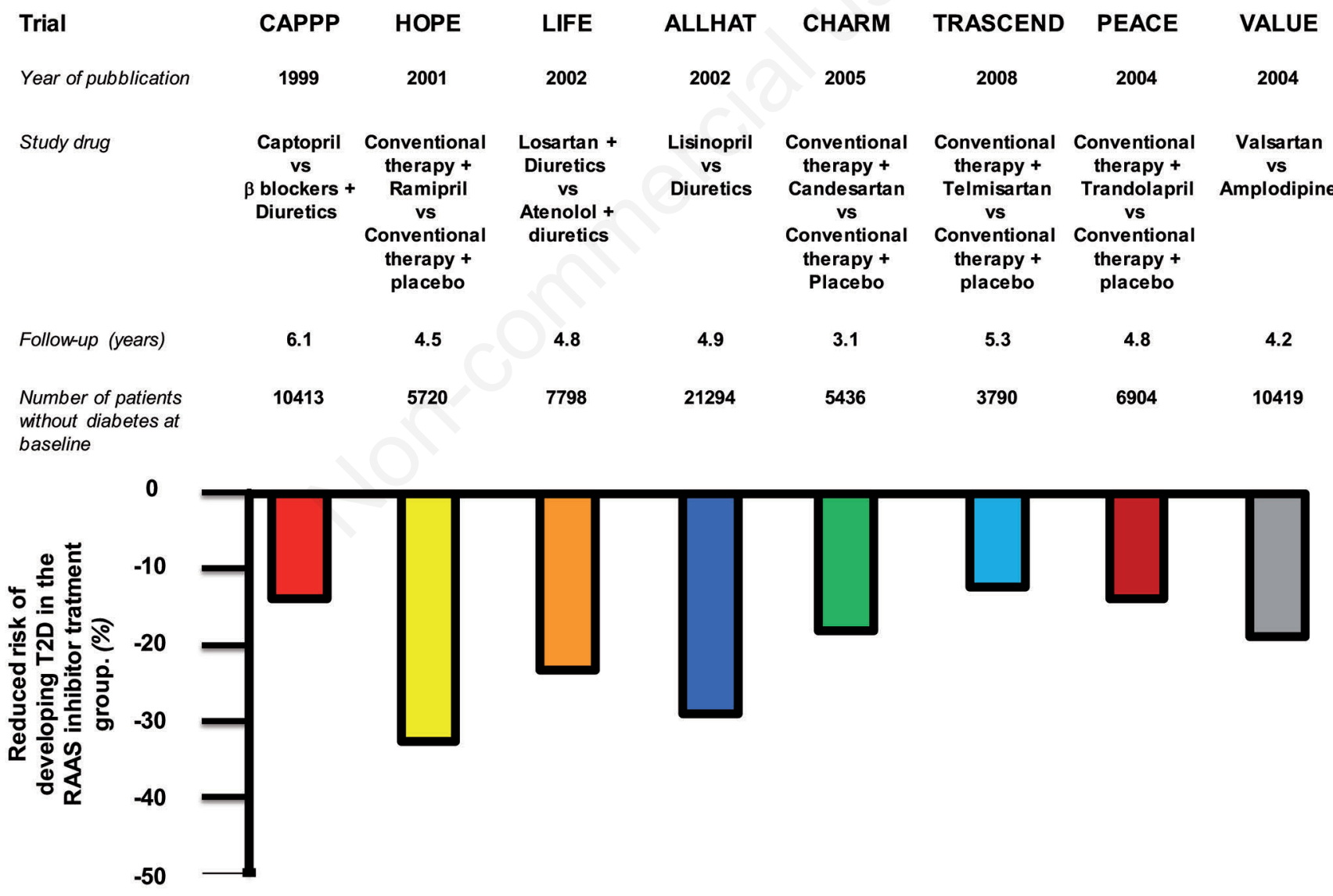

Figure 3. Results of principal intervention trials with renin-angiotensin-aldosterone system (RAAS) inhibitors on new diagnosis of diabetes (T2D). CAPP, Captopril prevention project; HOPE, Heart outcomes prevention evaluation; LIFE, Losartan intervention for endpoint reduction; ALLHAT, Antihypertensive and lipd lowering treatment to prevent heart attack trial; CHARM, Candesartan in heart failure-assessment of reduction in mortality and morbility; TRASCEND, Telmisartan Randomized Assessment Study in ACEI Intolerant Subjects with Cardiovascular Disease; PEACE, Prevention of events with angiotensin converting enzyme inhibition; VALUE, Valsartan antihypertensive long-term use evaluation. 
stimulate PPAR $\gamma$ [39], resulting in an improvement of insulin sensitivity [56]. This could indirectly influence systemic lipid concentrations.

The vulnerability of atherosclerotic plaque is a direct consequence of the crosstalk between the dysregulation of RAAS and hypercholesterolemia. Indeed, RAAS promotes through the expression of the collagen-degrading proteinases, the breakdown of the fibrous cup of the atheroma [57]. In addition, the RAAS stimulates also the activation of coagulation cascade and platelet aggregation. Ang II activates the Tissue Factor in monocytes and vascular endothelial cells [58], which in concert with further mediators such as coagulation factor II receptor, contribute to the pathogenesis coronary heart disease [59]. Notably, the gene encoding for coagulation factor II thrombin receptor, has been proposed as a marker of insulin resistance in MS, obesity, T2D, NAFLD, and atherosclerosis [60].

The beneficial effects of the RAAS inhibition to interfere with the development and progression of atherosclerosis are corroborated by several studies that evaluated the capability of ACEinhibitors and ARBs to prevent the major cerebrovascular and $\mathrm{CV}$ events (i.e., stroke and myocardial infarction) $[35,36,46]$.

\section{Metabolic syndrome and obesity}

MS and obesity are two manifestations of IR and are also independent determinants of structural and functional CV diseases [61-63]. In addition, both often are associated with abnormalities of renal function such us CKD and microalbuminuria $[64,65]$ which represents independent risk factors for CV diseases $[66,67]$. Adipose tissue acts as an endocrine organ, secreting hormones and other substances that create a proinflammatory state and promote formation of atherosclerotic plaques $[68,69]$.

\section{Experimental data}

The RAAS plays a key role in the link between obesity and cardio-renal damage. Adipose tissue is an important production site of angiotensinogen, and it has been reported a correlation among plasma level of angiotensinogen, BP, and body mass index. Moreover, in obese Zucker rats it has been documented an increase higher than $50 \%$ of gene expression of angiotensinogen, in adipose tissue compared with lean rats [70]. Interestingly, it has been also demonstrated that Ang II is implicated in the regulation of lipid synthesis and storage in the adipocytes, as well as, in the adipocyte growth and differentiation [71] In addition, it has been documented that the AT1R, and ACE genes were found to be upregulated in the adipose tissue of hypertensive patients with obesity [72]. Altogether these experimental evidence suggest a strong relationship between RAAS and regulation of functional activity of adipose tissue, this phenomenon could be involved in the increase of $\mathrm{CV}$ risk.

\section{Clinical data}

Many large interventional studies specifically addressed the effects of RAAS inhibition in MS. In particular, the hemodynamic and metabolic effects of two ARBs were evaluated: telmisartan and irbesartan. As pleiotropic effects, these molecules are known to activate PPAR- $\gamma$, a well-known target of insulin-sensitizing agents. In particular, the ISLAND study [73] demonstrated that administration of Irbesartan and/or Lipoic acid to patients with the MS improves endothelial function and reduces proinflammatory markers, Furthermore, it has been demonstrated the capability of Telmisartan to activates PPAR $\gamma$ in circulating monocytes of patients with the MS [74] The OLAS study evaluated the effects of different antihypertensive combination therapies on inflammatory and metabolic parameters in non-diabetic hypertensive patients with MS [75]. This study showed that olmesartan-based therapies were effective to reduce insulin resistance index $(24 \%$, $\mathrm{p}<0.01)$, to increase plasma adiponectin $(16 \%, \mathrm{p}<0.05)$ and to reduce the inflammation markers, with exception except for $\mathrm{C}$ reactive protein. In addition, the risk of new-onset of T2D was significantly reduced by Olmesartan-based treatments.

Experimental and clinical studies indicate that blocking the effects of Ang II (through ACE inhibition or ARBs) increases insulin sensitivity, which may contribute to the reduction of MS/obesity-mediated CV risk. Therefore, ACE inhibitors or ARBs represent the logical first-line anti-hypertensive agent in patients with MS or obesity.

\section{Non-pharmacological modulation of the RAAS and IR}

A large body of evidence demonstrates the benefits of physical exercise on $\mathrm{CV}$ risk physical exercise has a pleiotropic effect on cardio-metabolic homeostasis. In fact, it improves the vagal tone, enhances the synthesis, the release and the stability of NO, ameliorates the endothelial function, reduces the vascular inflammation, decreases the body weight and adiposity, improves the pancreatic $\beta$-cells function, restores the redox balance, increases hepatic fatty acid oxidation (Figure 4). In addition, experimental evidence indicates that the aerobic training modulates the RAAS activity, counterbalancing the detrimental effects of Ang II on insulin action [76]. Altogether these actions act in concert to improve the insulin sensitivity, and contribute to prevent the clinical manifestations of IR, such as metabolic syndrome, T2D, hypertension, and dyslipidemias [77]. From clinical point of view, the most powerful data about the beneficial effects of exercise on the reduction of CV risk, come from epidemiological and interventional studies that evaluated individuals at high risk for the development of T2D. In particular, the Chinese Da Qing Impaired Glucose Tolerance and Diabetes Study [78], the Finnish Diabetes Prevention [79], the Diabetes Prevention Program [80] showed that a prevention program based on lifestyle interventions that includes also a regular physical activity is able to reduce the incidence of the new diagnosis of T2D by $46-58 \%$. Although, the results of the lifestyle interventions in the prevention of T2D and IR are mainly ascribed to weight loss [81], it should be underlined that the exercise plays a key role to reduce and maintain the weight loss.

Several studies and meta-analyses have documented that all types of physical activity, such as the leisure time physical activity, the aerobic and the resistance training, or their combination, and the high intensity interval training are able to reduce the incident T2D or improve the insulin sensitivity [82-86]. Thus, nowadays, exercise training is highly recommended by the Scientific Societies for primary and secondary $\mathrm{CV}$ prevention. In particular, the ADA and AHA recommend reducing the CV risk to perform at least $150 \mathrm{~min}$ of moderate-intensity aerobic physical activity per week or, alternatively, at least $90 \mathrm{~min}$ of vigorous aerobic exercise per week $[87,88]$. Finally, there are few and weak data about the beneficial cardio-metabolic effects of uncommon physical activities like aquatic exercise, Nordic walking, Yoga, Pilates, Tai Chi, and dance [89-92]. However, these data need to be further confirmed by studies with larger cohort of individuals and with longer follow-up [93]. 


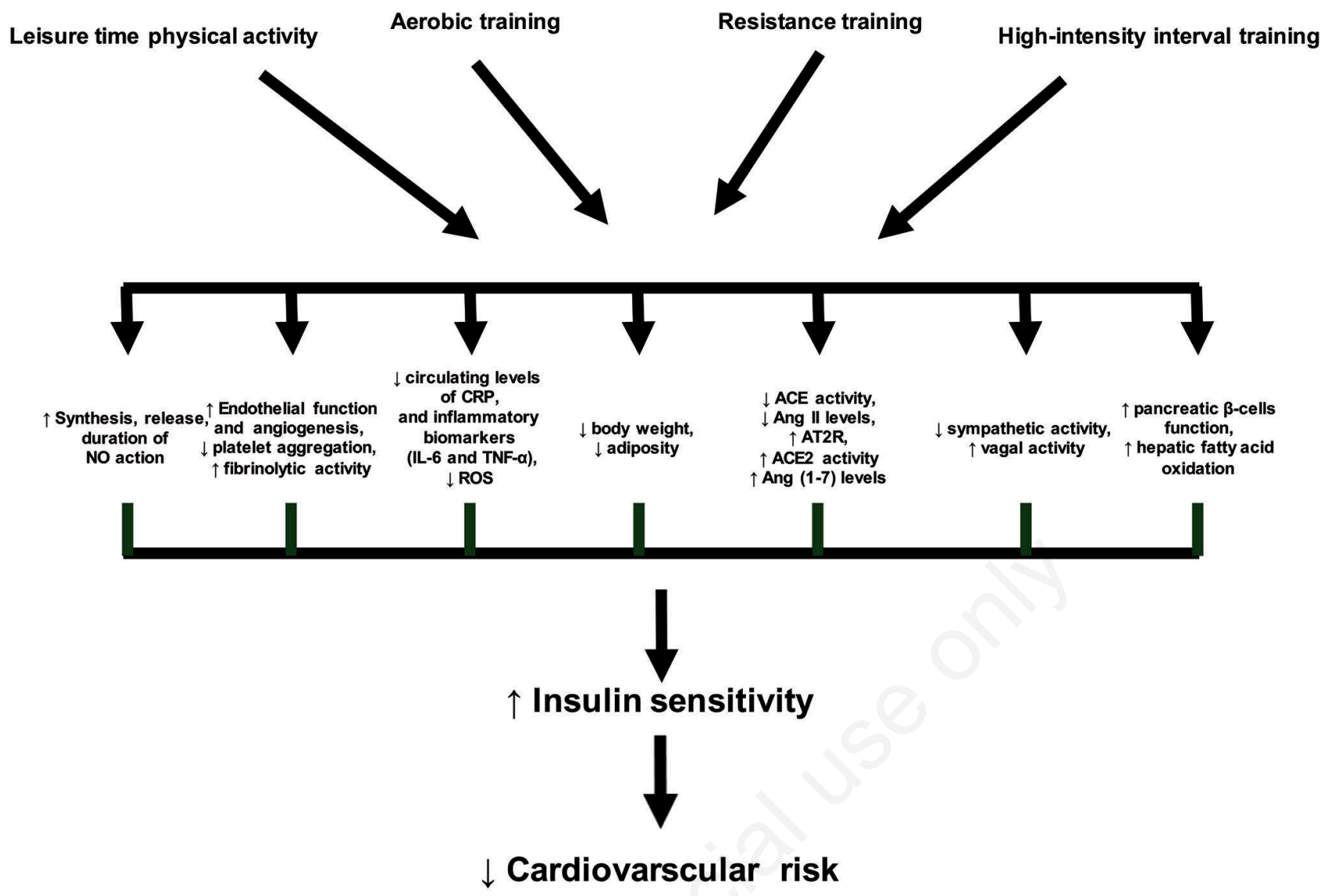

Figure 4. Exercise training-induced mechanisms that account for the reduction of cardiovascular risk. Notably, this is a complex and multifactorial process that is mediated by an improvement of insulin sensitivity. ACE, angiotensin converting enzyme; Ang, angiotensin; Ang II, angiotensin II; AT2R, type 2 angiotensin II receptor; CRP, C reactive protein; IL-6, interleukin-6; NO, nitric oxide; ROS, reactive oxygen species; TNF- $\alpha$, tumor necrosis factor- $\alpha$.

\section{Conclusions}

One of the paradigms of cardiology is that T2D accounts for development of atherosclerosis and CV complications. Nowadays, there are several evidence that show that TODs, rather to be the consequence, often precedee the development of T2D. Indeed, we have demonstrated that the severity of coronary atherosclerosis is predictive of development of T2D [94], and this phenomenon is mediated by IR [8]. Similarly, uncontrollated hypertension, and LVH precede the new diagnosis of T2D $[95,96]$. Consistently with this view IR needs to be considered the main target of therapeutic strategies aimed to reduce the cardio-metabiolic risk. This goal can be achieved by the integration of dietary changes, physical exercise [77], and pharmacological inhibition of RAAS.

\section{References}

1. Reaven G. The metabolic syndrome or the insulin resistance syndrome? Different names, different concepts, and different goals. EndocrinolMetabClin North Am 2004;33:283-303.

2. Olefsky J, Farquhar JW, Reaven G. Relationship between fast- ing plasma insulin level and resistance to insulin-mediated glucose uptake in normal and diabetic subjects. Diabetes 1973;22:507-13.

3. Sowers JR, Standley PR, Ram JL, et al. Hyperinsulinemia, insulin resistance, and hyperglycemia: contributing factors in the pathogenesis of hypertension and atherosclerosis. Am J Hypertens 1993;6:260S-70.

4. Wierzbicki AS, Oben J. Nonalcoholic fatty liver disease and lipids. Curr Opin Lipidol 2012;23:345-52.

5. Verdecchia P, Reboldi G, Schillaci G, et al. Circulating insulin and insulin growth factor-1 are independent determinants of left ventricular mass and geometry in essential hypertension. Circulation 1999;100:1802-7.

6. Xu H, Carrero JJ. Insulin resistance in chronic kidney disease. Nephrology (Carlton) 2017;224:31-4.

7. DeFronzo RA. Insulin resistance, lipotoxicity, type 2 diabetes and atherosclerosis: the missing links. The Claude Bernard Lecture 2009. Diabetologia 2010;53:1270-7.

8. Strisciuglio T, Izzo R, Barbato E, et al. Insulin resistance predicts severity of coronary atherosclerotic disease in non-diabetic patients. J Clin Med 2020;9:2144.

9. Lempiäinen P, Mykkänen L, Pyörälä K, et al. Insulin resistance syndrome predicts coronary heart disease events in elderly nondiabetic men. Circulation 1999;100:123-8. 
10. Jing J, Pan Y, Zhao X, et al. insulin resistance and prognosis of nondiabetic patients with ischemic stroke: The ACROSSChina Study (Abnormal Glucose Regulation in patients with acute stroke across China). Stroke 2017;48:887-93.

11. Ago T, Matsuo R, Hata J, et al. Insulin resistance and clinical outcomes after acute ischemic stroke. Neurology 2018;90:e1470-7.

12. Uetani $\mathrm{T}$, Amano $\mathrm{T}$, Harada $\mathrm{K}$, et al. Impact of insulin resistance on post-procedural myocardial injury and clinical outcomes in patients who underwent elective coronary interventions with drug-eluting stents. JACC Cardiovasc Interv 2012;5:1159-67.

13. Swan JW, Anker SD, Walton $\mathrm{C}$, et al. Insulin resistance in chronic heart failure: relation to severity and etiology of heart failure. J Am Coll Cardiol 1997;30:527-32.

14. Morisco C, Lembo G, Trimarco B. Insulin resistance and cardiovascular risk: New insights from molecular and cellular biology. Trends Cardiovasc Med 2006;16:183-8.

15. Fiordelisi A, Iaccarino G, Morisco C, et al. NFkappaB is a key player in the crosstalk between inflammation and cardiovascular diseases. Int J Mol Sci 2019;20:1599.

16. Erdös EG. Angiotensin I convertingenzyme. Circ Res 1975;36:247-55.

17. Fryer LG, Hajduch E, Rencurel F, et al. Activation of glucose transport by AMP-activated protein kinase via stimulation of nitric oxide synthase. Diabetes 2000;49:1978-85.

18. Henriksen EJ, Jacob S, Kinnick TR, et al. ACE inhibition and glucose transport in insulinresistant muscle: roles of bradykinin and nitric oxide. Am J Physiol 1999;277:R332-6.

19. Morel Y, Gadient A, Keller U, et al. Insulin sensitivity in obese hypertensive dyslipidemic patients treated with enalapril or atenolol. J Cardiovasc Pharmacol 1995;26:306-11.

20. Pollare T, Lithell H, Berne C. A comparison of the effects of hydrochlorothiazide and captopril on glucose and lipid metabolism in patients with hypertension. $N$ Engl J Med 1989;321:868-73.

21. Sharma AM, Janke J, Gorzelniak K, et al. Angiotensin blockade prevents type 2 diabetes by formation of fat cells. Hypertension 2002;40:609-11.

22. Carlsson PO, Berne C, Jansson L. Angiotensin II and the endocrine pancreas: effects on islet blood flow and insulin secretion in rats. Diabetologia 1998;41:127-33.

23. Arbin V, Claperon N, Fournié-Zaluski MC, et al. Acute effect of the dual angiotensin-converting enzyme and neutral endopeptidase 24-11 inhibitor mixanpril on insulin sensitivity in obese Zucker rat. Br J Pharmacol 2001;133:495-502.

24. Uehara M, Kishikawa H, Isami S, et al. Effect on insulin sensitivity of angiotensin converting enzyme inhibitors with or without a sulphydryl group: bradykinin may improve insulin resistance in dogs and humans. Diabetologia 1994;37:300-7.

25. Dal Ponte DB, Fogt DL, Jacob S, Henriksen EJ. Interactions of captopril and verapamil on glucose tolerance and insulin action in an animal model of insulin resistance. Metabolism 1998;47:982-7.

26. Steen MS, Foianini KR, Youngblood EB, et al. Interactions of exercise training and ACE inhibition on insulin action in obese Zucker rats. J Appl Physiol (1985) 1999;86:2044-51.

27. Nawano M, Anai M, Funaki M, et al. Imidapril, an angiotensin-converting enzyme inhibitor, improves insulin sensitivity by enhancing signal transduction via insulin receptor substrate proteins and improving vascular resistance in the Zucker fatty rat. Metabolism 1999;48:1248-55.

28. Shiuchi T, Cui TX, Wu L, et al. ACE inhibitor improves insulin resistance in diabetic mouse via bradykinin and $\mathrm{NO}$ Hypertension 2002;40:329-34.

29. Henriksen EJ, Jacob S. Effects of captopril on glucose transport activity in skeletal muscle of obese Zucker rats. Metabolism 1995;44:267-72.

30. Jacob S, Henriksen EJ, Fogt DL, Dietze GJ. Effects of trandolapril and verapamil on glucose transport in insulin-resistant rat skeletal muscle. Metabolism 1996;45:535-41.

31. Rett K, Wicklmayr M, Dietze GJ, Häring HU. Insulin-induced glucose transporter (GLUT1 and GLUT4) translocation in cardiac muscle tissue is mimicked by bradykinin. Diabetes 1996;45:S66-9.

32. Mazzone G, Morisco C, Lembo V, et al. Dietary supplementation of vitamin D prevents the development of western dietinduced metabolic, hepatic and cardiovascular abnormalities in rats. United European Gastroenterol J 2018;6:1056-64.

33. Toblli JE, Muñoz MC, Cao G, et al. ACE inhibition and AT1 receptor blockade prevent fatty liver and fibrosis in obese Zucker rats. Obesity (Silver Spring) 2008;16:770-6.

34. Hansson L, Lindholm LH, Niskanen L, et al. Effect of angiotensin-converting-enzyme inhibition compared with conventional therapy on cardiovascular morbidity and mortality in hypertension: the Captopril Prevention Project (CAPPP) randomised trial. Lancet 1999;353:611-6.

35. Heart Outcomes Prevention Evaluation Study Investigators, Yusuf S, Sleight P, et al. Effects of an angiotensin-convertingenzyme inhibitor, ramipril, on cardiovascular events in highrisk patients. [Errata in: 2000 May 4;342:1376 - N Engl J Med 2000;342:748]. N Engl J Med 2000;342:145-53.

36. ALLHAT Officers and Coordinators for the ALLHAT Collaborative Research Group. The Antihypertensive and Lipid-Lowering Treatment to Prevent Heart Attack Trial. Major outcomes in high-risk hypertensive patients randomized to angiotensin-converting enzyme inhibitor or calcium channel blocker vs diuretic: The Antihypertensive and Lipid-Lowering Treatment to Prevent Heart Attack Trial (ALLHAT) [Errata in JAMA 2003;289:178 - JAMA 2004;291:2196]. JAMA 2002;288:2981-97.

37. Braunwald E, Domanski MJ, Fowler SE, et al. Angiotensinconverting-enzyme inhibition in stable coronary artery disease. N Engl J Med 2004;351:2058-68.

38. Borém LMA, Neto JFR, Brandi IV, et al. The role of the angiotensin II type I receptor blocker telmisartan in the treatment of non-alcoholic fatty liver disease: a brief review. Hypertens Res 2018;41:394-405.

39. Schupp M, Janke J, Clasen R, et al. Angiotensin type 1 receptor blockers induce peroxisome proliferator-activated receptorgamma activity. Circulation 2004;109:2054-57.

40. Schupp M, Lee LD, Frost N, et al. Regulation of peroxisome proliferator-activated receptor gamma activity by losartan metabolites. Hypertension 2006;47:586-9.

41. Guerre-Millo M, Gervois P, RAASpé E, et al. Peroxisome proliferator-activated receptor alpha activators improve insulin sensitivity and reduce adiposity. J Biol Chem 2000;275:16638-42.

42. Chou CJ, Haluzik M, Gregory C, et al. WY14,643, a peroxisome proliferator-activated receptor alpha (PPARalpha ) agonist, improves hepatic and muscle steatosis and reverses insulin resistance in lipoatrophic A-ZIP/F-1 mice. J Biol Chem 2002;277:24484-9.

43. Müller-Fielitz H, Hübel N, Mildner M, et al. Chronic blockade of angiotensin $\mathrm{AT}_{1}$ receptors improves cardinal symptoms of metabolic syndrome in diet-induced obesity in rats. $\mathrm{Br} \mathrm{J}$ Pharmacol 2014;171:746-60. 
44. Abuissa H, Jones PG, Marso SP, O'Keefe JH Jr. Angiotensinconverting enzyme inhibitors or angiotensin receptor blockers for prevention of type 2 diabetes: a meta-analysis of randomized clinical trials. J Am Coll Cardiol 2005;46:821-6.

45. Elliott WJ, Meyer PM. Incident diabetes in clinical trials of antihypertensive drugs: a network meta-analysis [Erratum in: Lancet 2007;369:1518]. Lancet 2007;369:201-7.

46. Telmisartan Randomised AssessmeNt Study in ACE iNtolerant subjects with cardiovascular Disease (TRANSCEND) Investigators, Yusuf S, Teo K, et al. Effects of the angiotensinreceptor blocker telmisartan on cardiovascular events in highrisk patients intolerant to angiotensin-converting enzyme inhibitors: a randomised controlled trial [Erratum in: Lancet 2008;372:1384]. Lancet 2008;372:1174-83.

47. Carpinella G, Pagano G, Buono F, et al. Prognostic value of combined target-organ damage in patients with essential hypertension. Am J Hypertens 2015;28:127-34.

48. Daugherty A, Rateri DL, Lu H, et al. Hypercholesterolemia stimulates angiotensin peptide synthesis and contributes to atherosclerosis through the AT1A receptor. Circulation 2004;110:3849-57.

49. Kanome T, Watanabe T, Nishio K, et al. Angiotensin II upregulates acyl-CoA: cholesterol acyltransfeRAASe-1 via the angiotensin II Type 1 receptor in human monocytemacrophages. Hypertens Res 2008;31:1801-10.

50. Putnam K, Shoemaker R, Yiannikouris F, Cassis LA. The renin-angiotensin-aldosterone system: a target of and contributor to dyslipidemias, altered glucose homeostasis, and hypertension of the metabolic syndrome. Am J Physiol Heart Circ Physiol 2012;302:H1219-30.

51. Li D, Saldeen T, Romeo F, Mehta JL. Oxidized LDL upregulates angiotensin II type 1 receptor expression in cultured human coronary artery endothelial cells: the potential role of transcription factor NF-kappaB. Circulation 2000;102:1970-6.

52. Buono F, Spinelli L, Giallauria F, et al. Usefulness of satisfactory control of low-density lipoprotein cholesterol to predict left ventricular remodeling after a first ST-elevation myocardial infarction successfully reperfused. Am J Cardiol 2011;107:1772-8.

53. Kyvelou SM, Vyssoulis GP, Karpanou EA, et al. Effects of antihypertensive treatment with angiotensin II receptor blockers on lipid profile: an open multi-drug comparison trial. Hellenic J Cardiol 2006;47:21-8.

54. Olsen MH, Wachtell K, Beevers G, et al. Effects of losartan compared with atenolol on lipids in patients with hypertension and left ventricular hypertrophy: the Losartan Intervention For Endpoint reduction in hypertension study. J Hypertens 2009;27:567574.

55. Lindholm LH, Persson M, Alaupovic P, et al. Metabolic outcome during 1 year in newly detected hypertensives: results of the Antihypertensive Treatment and Lipid Profile in a North of Sweden Efficacy Evaluation (ALPINE study). J Hypertens 2003;21:1563-74.

56. Parhofer KG, Münzel F, Krekler M. Effect of the angiotensin receptor blocker irbesartan on metabolic parameters in clinical practice: the DO-IT prospective observational study. Cardiovasc Diabetol 2007;6:36.

57. Libby P. Molecular bases of the acute coronary syndromes. Circulation 1995;91:2844-50.

58. Celi A, Cianchetti S, Dell'Omo G, Pedrinelli R. Angiotensin II, tissue factor and the thrombotic paradox of hypertension. Expert Rev Cardiovasc Ther 2010;8:1723-9.

59. Gigante B, Bellis A, Visconti R, et al. Retrospective analysis of coagulation factor II receptor (F2R) sequence variation and coronary heart disease in hypertensive patients. Arterioscler Thromb Vasc Biol 2007;27:1213-9.

60. Yi X, Wu P, Liu J, et al. Identification of the potential key genes for adipogenesis from human mesenchymal stem cells by RNA-seq. J Cell Physiol 2019;234 20217-27.

61. Buono F, Crispo S, Pagano G, et al. Determinants of left ventricular hypertrophy in patients with recent diagnosis of essential hypertension. J Hypertens 2014;32:166-73.

62. Kenchaiah S, Evans JC, Levy D, et al. Obesity and the risk of heart failure. N Engl J Med 2002;347:305-13.

63. Rexrode KM, Carey VJ, Hennekens CH, et al. Abdominal adiposity and coronary heart disease in women. JAMA 1998;280:1843-8.

64. Pazos F. Range of adiposity and cardiorenal syndrome. World J Diabetes 2020;11:322-50.

65. Nistala R, Whaley-Connell A. Resistance to insulin and kidney disease in the cardiorenal metabolic syndrome; role for angiotensin II. Mol Cell Endocrinol 2013;378:53-8.

66. Meccariello A, Buono F, Verrengia E, et al. Microalbuminuria predicts the recurrence of cardiovascular events in patients with essential hypertension. J Hypertens 2016;34:646-53.

67. Gerstein HC, Mann JF, Yi Q, et al. Albuminuria and risk of cardiovascular events, death, and heart failure in diabetic and nondiabetic individuals. JAMA 2001;286:421-6.

68. Lau DC, Dhillon B, Yan H, et al. Adipokines: molecular links between obesity and atheroslcerosis. Am J Physiol Heart Circ Physiol 2005;288:H2031-41.

69. Trayhurn P, Wood IS. Adipokines: inflammation and the pleiotropic role of white adipose tissue. $\mathrm{Br} \mathrm{J}$ Nutr 2004;92:347355.

70. Jones BH, Standridge MK, Taylor JW, Moustaïd N. Angiotensinogen gene expression in adipose tissue: analysis of obese models and hormonal and nutritional control. Am J Physiol 1997;273:R236-42.

71. Engeli S, Sharma AM. Role of adipose tissue for cardiovascular-renal regulation in health and disease. Horm Metab Res 2000;32:485-99.

72. Gorzelniak K, Engeli S, Janke J, Luft FC, Sharma AM. Hormonal regulation of the human adipose-tissue reninangiotensin-aldosterone system: relationship to obesity and hypertension. J Hypertens 2002;20:965-73.

73. Sola S, Mir MQ, Cheema FA, et al. Irbesartan and lipoic acid improve endothelial function and reduce markers of inflammation in the metabolic syndrome: results of the Irbesartan and Lipoic Acid in Endothelial Dysfunction (ISLAND) study. Circulation 2005;111:343-8.

74. Bähr IN, Tretter P, Krüger J, et al. High-dose treatment with telmisartan induces monocytic peroxisome proliferator-activated receptor- $\gamma$ target genes in patients with the metabolic syndrome. Hypertension 2011;58:725-32.

75. Martinez-Martin FJ, Rodriguez-Rosas H, Peiro-Martinez I, et al. Olmesartan/amlodipine vs olmesartan/hydrochlorothiazide in hypertensive patients with metabolic syndrome: the OLAS study. J Hum Hypertens 2011;25:346-53.

76. Fernandes T, Hashimoto NY, Magalhães FC, et al. Aerobic exercise training-induced left ventricular hypertrophy involves regulatory MicroRNAs, decreased angiotensin-converting enzyme-angiotensin ii, and synergistic regulation of angiotensin-converting enzyme 2-angiotensin (1-7). Hypertension 2011;58:182-9.

77. Iaccarino G, Franco D, Sorriento D, et al. Modulation of insulin sensitivity by exercise training: Implications for cardio- 
vascular prevention. J Cardiovasc Transl Res 2020. doi: 10.1007/s12265-020-10057-w. Online ahead of print.

78. Pan XR, Li GW, Hu YH, et al. Effects of diet and exercise in preventing NIDDM in people with impaired glucose tolerance. The Da Qing IGT and Diabetes Study. Diabetes Care 1997;20:537-44.

79. Tuomilehto J, Lindström J, Eriksson JG, et al. Prevention of type 2 diabetes mellitus by changes in lifestyle among subjects with impaired glucose tolerance. N Engl J Med 2001;34:1343-50.

80. Knowler WC, Barrett-Connor E, Fowler SE, et al. Reduction in the incidence of type 2 diabetes with lifestyle intervention or metformin. N Engl J Med 2002;346:393-403.

81. Hamman RF, Wing RR, Edelstein SL, et al. Effect of weight loss with lifestyle intervention on risk of diabetes. Diabetes Care 2006;29:2102-7.

82. Lao XQ, Deng HB, Liu X, et al. Increased leisure-time physical activity associated with lower onset of diabetes in 44828 adults with impaired fasting glucose: a population-based prospective cohort study. Br J Sports Med 2019;53:895-900.

83. Aune D, Norat T, Leitzmann M, et al. Physical activity and the risk of type 2 diabetes: a systematic review and dose-response meta-analysis. Eur J Epidemiol 2015;30:529-42.

84. Orozco LJ, Buchleitner AM, Gimenez-Perez G, et al. Exercise or exercise and diet for preventing type 2 diabetes mellitus. Cochrane Database Syst Rev 2008;(3):CD003054.

85. Chudyk A, Petrella RJ. Effects of exercise on cardiovascular risk factors in type 2 diabetes: a meta-analysis. Diabetes Care 2011;34:1228-37.

86. Campbell WW, Kraus WE, Powell KE, et al. High-intensity interval training for cardiometabolic disease prevention. Med Sci Sports Exerc 2019;5:1220-6.

87. American Diabetes Association. 3. Prevention or delay of type
2 diabetes: Standards of medical care in diabetes-2020. Diabetes Care 2020;43:S32-6.

88. Buse JB, Ginsberg HN, Bakris GL, et al. Primary prevention of cardiovascular diseases in people with diabetes mellitus: a scientific statement from the American Heart Association and the American Diabetes Association. Diabetes Care 2007;30:162-72.

89. Borges L, Passos MEP, Silva MBB, et al. Dance training improves cytokine secretion and viability of neutrophils in diabetic patients. Mediators Inflamm 2019;2019:2924818.

90. Melo KCB, Araújo FS, Cordeiro Júnior CCM, et al. Pilates method training: functional and blood glucose responses of older women with type 2 diabetes. J Strength Cond Res 2020;34:1001-7.

91. Cugusi L, Cadeddu C, Nocco S, et al. Effects of an aquaticbased exercise program to improve cardiometabolic profile, quality of life, and physical activity levels in men with type 2 diabetes mellitus. PM R 2015;7:141-8; quiz 148.

92. Krishnan S, Tokar TN, Boylan MM, et al. Zumba ${ }^{\circledR}$ dance improves health in overweight/obese or type 2 diabetic women. Am J Health Behav 2015;39:109-20.

93. Crisafulli A, Pagliaro P, Roberto S, et al. Diabetic cardiomyopathy and ischemic heart disease: Prevention and therapy by exercise and conditioning. Int J Mol Sci 2020;21:2896.

94. Colaiori I, Izzo R, Barbato E, et al. Severity of coronary atherosclerosis and risk of diabetes mellitus. J Clin Med 2019;8:1069.

95. Izzo R, de Simone G, Chinali M, et al. Insufficient control of blood pressure and incident diabetes. Diabetes Care 2009;32:845-50.

96. Izzo R, de Simone G, Trimarco V, et al. Hypertensive target organ damage predicts incident diabetes mellitus. Eur Heart J 2013;34:3419-26. 